\title{
Aligning brownfields remediation to transit oriented development
}

\author{
M. A. Sloan \& B. T. Bidolli \\ Greater Bridgeport Regional Council, USA
}

\begin{abstract}
Located in the State of Connecticut, the two urban communities of Bridgeport and Stratford have been burdened by brownfield properties and the barriers to growth caused by this environmental contamination. Both communities are key nodes on a major rail corridor but, due to brownfield properties, have not yet realized the development opportunities that this infrastructure can support: a vibrant mix of businesses, housing and services aligned to a robust transit network. The Greater Bridgeport Regional Council has partnered with these two communities to develop a holistic program, which will focus remediation activities on contaminated properties in transit supportive locations.

Remediation and redevelopment activities will be coordinated with the Regional Transit Oriented Development Pilot Program, a planning program that will determine the strategies necessary to link these transit supportive neighbourhoods via efficient, effective and convenient modes of public transit. Ultimately, the coordination of these two efforts will result in the repositioning of undevelopable land into a linear transit community and will revitalize neighbourhoods that these sites have blighted for decades.

Keywords: brownfields, transit oriented development, sustainable, neighbourhood revitalization.
\end{abstract}

\section{Introduction}

The economic constraints to local governments posed by brownfield properties are exacerbated by lower revenues and budget shortfalls, thus limiting the capacity of local governments to remediate and fully realize the post-industrial development potential of these properties. The sustainable social, economic and environmental reuse of these properties may be achieved by targeting this limited 
remediation funding to properties that have received a high level of developer interest and which are located in close proximity to existing infrastructure, such as a multi-modal transportation corridor.

Until the late $20^{\text {th }}$ century, Bridgeport and Stratford were thriving industrial centres: many neighbourhoods developed around the large manufacturing complexes and factories which employed a significant portion of the two community's populations. The decline of industry in these communities has resulted in limited employment opportunities, large tracts of vacant, contaminated land and neighbourhoods that are dominated by acres of ruined factory complexes.

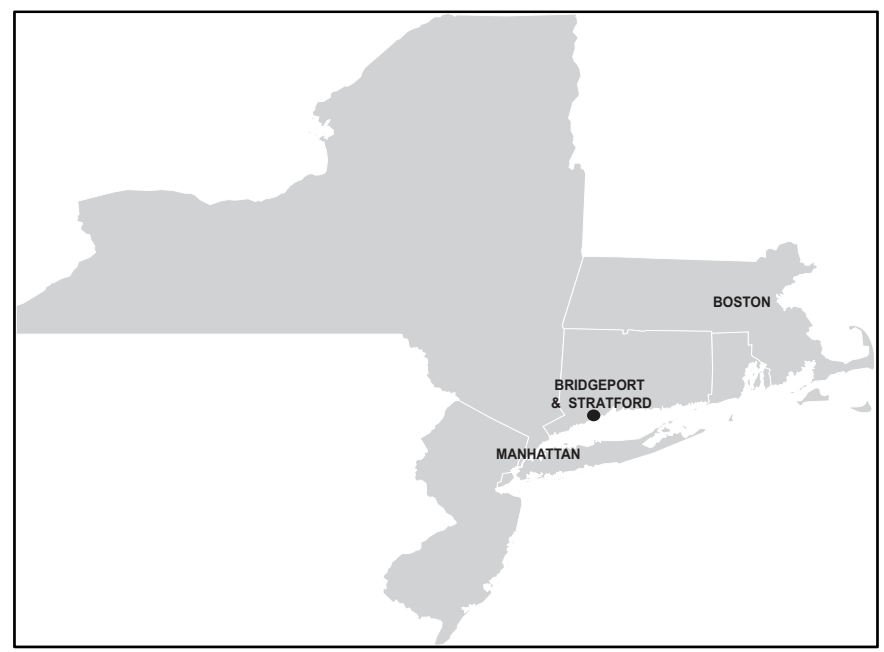

Figure 1: State of Connecticut and study area.

\subsection{Study area}

One of the smallest states in the country, Connecticut is located in Southern New England and is situated between New York and Massachusetts (see Figure 1). Lying on the Long Island Sound coastline (in eastern Fairfield county), the City of Bridgeport and Town of Stratford are both stops on Metro-North Railroad's New Haven Main Line - one of the most heavily travelled rail corridors in the country. Total annual ridership is estimated at 37.7 million passengers, with average weekday boardings of 1,427 in Stratford and 3,110 in Bridgeport [1]. This service is crucial to the Connecticut economy, as it provides access to the New York City metropolitan area market and a diversity of employment opportunities.

The combined population of Bridgeport and Stratford is estimated to be 194,528 people. As the most populous city in the state, Bridgeport makes up the majority of this population with 143,412 people [2]. For many residents of Bridgeport and Stratford, employment and economic opportunities are oriented toward southwestern Fairfield County and the New York metropolitan area, 
rather than their place of residence. In Bridgeport, out of an estimated 61,203 workers, only $31 \%$ are estimated to work in the city, with $11 \%$ of workers estimated to work outside of Fairfield County and 5\% outside of the state. With an estimated 24,706 workers, only $22 \%$ of workers in Stratford are estimated to work within the town, with $18 \%$ of workers commuting outside of Fairfield County and $5 \%$ of workers commuting outside of the state. Mean travel time to work for both communities is between 26 and 28 minutes [3]. Clearly, local employment opportunities are limited, further underscored by the number of jobs available: in 2012, only 41,190 jobs were counted in Bridgeport [4].

The 800+ acres of vacant land in Bridgeport and 70+ acres of brownfields in Stratford represent the gradual disappearance of the region's manufacturing sector through the mid and late $20^{\text {th }}$ century. A new economic base and associated (and much needed) job opportunities were not realized. The land that had once supported the region's manufacturing economy was not repurposed for new uses, often because of the contamination caused by decades of poor waste management and hazardous materials disposal practices $[5,6]$. The remediation of these sites is the first step to bringing them back to productive use, and will ultimately unlock new employment and economic opportunities. These large tracts of land prime for redevelopment are anticipated to serve as destinations easily accessible via rail and are key components in the revitalization strategies of both communities.

\subsection{Problem description}

The State of Connecticut defines a brownfield as "any abandoned or underutilized site where redevelopment, reuse or expansion has not occurred due to the presence or potential presence of pollution in the buildings, soil or groundwater that requires investigation or remediation before or in conjunction with the restoration, redevelopment, reuse and expansion of the property." [7]. This definition illustrates the dampening effect brownfields have on property owners, neighbourhoods, the local economy and local governments. The full value of a property (and often neighbouring properties) can only be realized through remediation. However, sources to fund remediation are severely limited.

Standalone, parcel-by-parcel remediation projects do not always make the best use of these limited resources. A 2010 Brookings report identified the need for greater coordination between the EPA brownfields programs, other federal programs and state programs to ensure the effective leveraging of these resources, as well as the need for cities to develop sustainable long term neighbourhood stabilization strategies that effectively utilize local and federal funds [8]. An approach to brownfields revitalization that is centered around the comprehensive redevelopment of a transportation corridor or neighbourhood, rather than a parcel-by-parcel process guided by the priorities of individual developers [9] may ultimately realize a community's long term vision for sustainable redevelopment. Concurrently, a planning and regulatory framework for transit oriented development that defines the community's redevelopment vision sets appropriate expectations and creates certainty for developers when proposing a project [10]. 
The Brookings report [8] emphasizes the importance of transportation investments in supporting the economic competiveness of distressed, urban areas: "The point of making transportation investments in these cities is not to respond to existing economic activity, but to serve as a catalyst for potential economic development and neighborhood revitalization opportunities." (36). Clearly, all levels of government, as well as local stakeholders have an opportunity to develop comprehensive and holistic neighbourhood revitalization strategies that include plans for brownfield reuse, transportation, conservation, land use and economic development.

\subsubsection{Economic impacts of brownfields}

Realizing the full economic potential of land is crucial for local governments in the State of Connecticut, as the property tax is the main revenue source for most municipalities throughout the state [11]. State statute does not allow for the levying of local sales or income taxes. Between 2010 and 2011, the property tax made up an average of $71.9 \%$ of municipal revenue in Connecticut [12]. Land that is under-utilized, in foreclosure, vacant or municipally owned reduces local property tax revenue and limits the capacity of local government to adequately address and fund brownfield redevelopment. Often, these brownfield sites also cause the value of surrounding properties to decrease [13]; further reducing the amount of property tax revenue a local government may collect.

\subsubsection{Social impacts of brownfields}

Vacant, abandoned and underutilized properties undermine more than the economic value of neighbouring properties; these sites also impact a neighbourhood's social fabric. If a property is neglected or poorly maintained, trash and weeds take over the lot and deteriorating structures may visibly blight an entire block or neighbourhood. Abandoned buildings attract illegal activities such as prostitution and drug use, while empty lots are used for illegal dumping $[14,15]$. The cumulative impact of these factors can cause a decline in the quality of life for residents, businesses and other stakeholders in a neighbourhood.

\subsubsection{Environmental impacts of brownfields}

Beyond the inherent environmental damage to land and water caused by contamination, a brownfield has both local and regional environmental impacts. Developer concern about site contamination in developed, urban areas is likely to redirect growth and development to environmentally valuable greenfield sites. These sites may have been used for agriculture and/or provided ecological services - such as open space or habitat for native species. The development of a greenfield site reduces ecological services in a region, which cannot be "re-located" to another site. Infrastructure, such as roads, sewer lines and utilities have to be built or extended to serve the new development, putting a further strain on the environment through materials use, disturbances caused by construction and ongoing maintenance. Brownfield sites are typically served by existing infrastructure - but the investment in this infrastructure is left unrealized if the site is not in use $[16,17]$. 


\section{Project description}

\subsection{Brownfields redevelopment}

In October of 2013, the Greater Bridgeport Regional Council was awarded a \$400,000 Brownfields Assessment Grant by the United States Environmental Protection Agency (EPA) to prioritize and assess brownfield sites for clean-up and reuse in the City of Bridgeport and the Town of Stratford. The purpose of EPA Brownfields Program funding is to "empower states, communities, tribes, and non-profits to inventory, assess, clean up and reuse brownfield properties" [18].

The GBRC Brownfields Assessment program is targeted toward two discrete areas that have received attention from the medical and educational sectors, as well as from developers interested in mixed use development: Downtown Stratford's Transit Centered Development (TCD) district and the East Bridgeport Development Corridor, which runs through the East Side and East End neighbourhoods of Bridgeport. The two targeted investment areas for Brownfields Assessment funding spatially align with the targeted study areas in a region-wide planning program: the Regional Transit Oriented Development (TOD) Pilot Program. The ultimate goal of this regional program is to develop a strategy to link the Greater Bridgeport Region's commuter rail stations and to reposition the surrounding land as connected, linear transit communities.

Utilizing the EPA Assessment funding is the first phase in returning key, priority sites to their highest and best use. The Regional TOD Pilot Program will provide the framework with which to guide improvements to rail and bus service in the East Bridgeport Development Corridor and Stratford TCD District (both illustrated in Figure 2). Land use and zoning policies that are supportive of transit accessibility, walkability and a mix of uses (residential, retail, office and light industrial) will alleviate some of the uncertainty that often accompanies property redevelopment [9]. Mechanisms that support a swift investment, remediation and redevelopment process, coupled with improvements to transit are intended to sustain developer interest and ultimately revitalize surrounding neighbourhoods.

\subsection{Transit oriented development}

The Regional Transit Oriented Development (TOD) Pilot Program is composed of multiple, inter-dependent planning projects and is funded through a variety of sources and recipient entities. Greater Bridgeport Transit (GBT) provides fixed route and demand response bus service to the Greater Bridgeport Region and is the program lead. The GBT is the recipient of $\$ 320,000$ in Federal Transit Administration funding for an assessment of alternative modes and the development of a long range transit plan for the Greater Bridgeport Region. The Town of Stratford was awarded $\$ 225,000$ by the State of Connecticut to plan a Transit Centered Development District in the Town Center. The Greater Bridgeport Regional Council was awarded $\$ 25,000$ from the same source to 


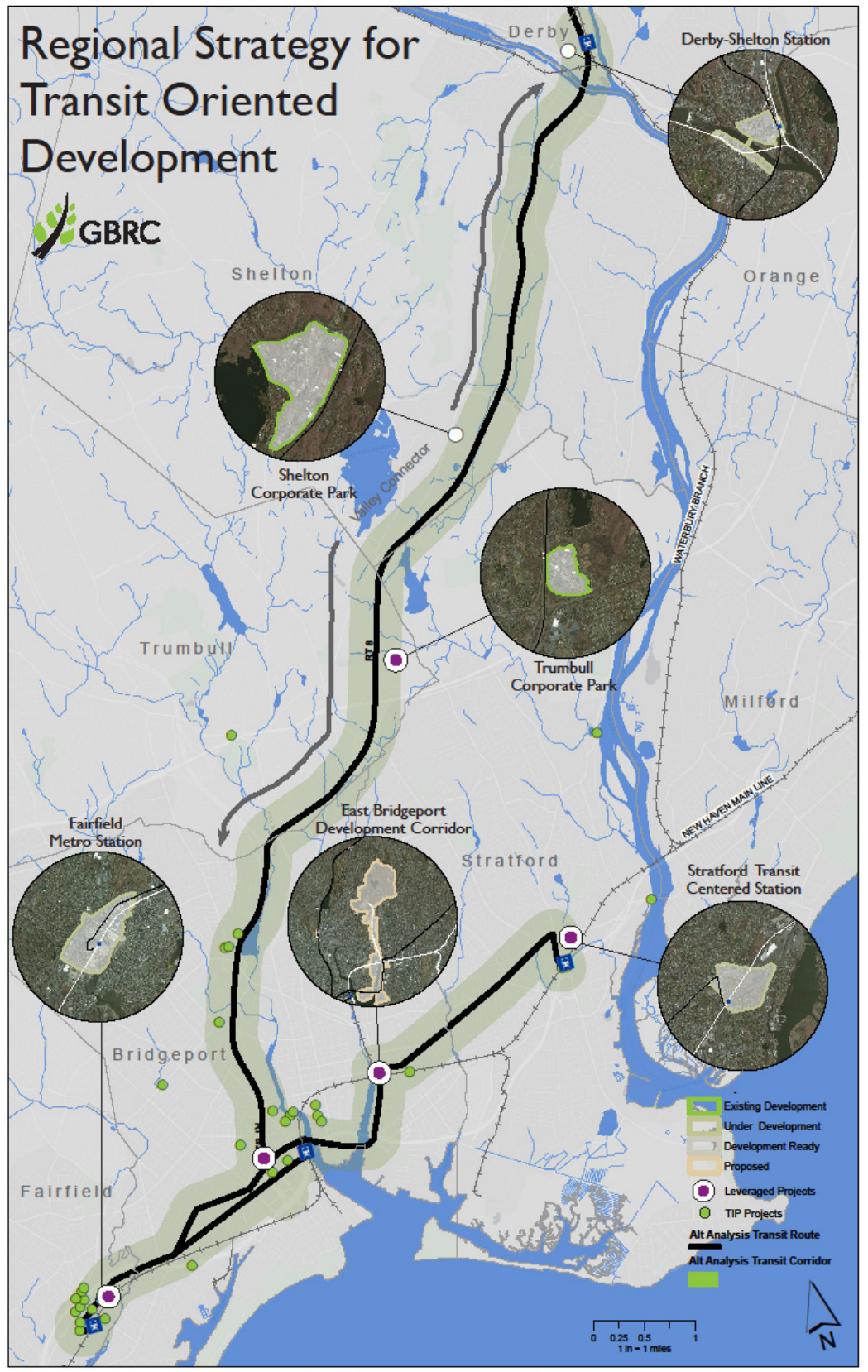

Figure 2: Regional TOD strategy. 
develop a Model TOD Zoning Ordinance for the Region. The City of Bridgeport was awarded \$400,000 in Federal Highway Administration (FHWA) STP Urban funding for an assessment of transportation alternatives in the East BridgeportSeaview Avenue Development Corridor. The funds provided by the State of Connecticut to the Town of Stratford and the GBRC will be used to partially fulfil match requirements for the federal transportation funding. Core tasks of the program are as follows:

- Identify the locally preferred public transit alternatives to link existing, planned and proposed transit oriented and supportive districts and neighbourhoods.

- Develop short-, mid- and long-term transit services plans.

- Identify strategies and actions to convert the Stratford Town Center area into a spatially connected district with safe and convenient pedestrian linkages and transit-supportive densities.

- Identify strategies and actions to transform the land uses around the region's rail stations from automobile dependent uses to those supported by rail access.

- Develop a model TOD Zoning Ordinance for the Greater Bridgeport Region.

The Regional TOD Pilot Program is a model of regional cooperation: two local governments, a regional entity and a regional transit authority successfully worked with state and federal government to maximize the extent of limited funding. Adjacent municipalities, including the Towns of Fairfield and Trumbull have also been invited to participate on the project advisory committee. Three rail stations are located in the Town of Fairfield; the recently opened Fairfield Metro Center station is located in close proximity to Bridgeport. Rail stations in Bridgeport, Fairfield and Stratford serve commuters from the Town of Trumbull.

\subsection{Barnum station feasibility study}

The Barnum Station Feasibility Study was a precursor to the Regional TOD Pilot Program and evaluated the feasibility of a second commuter rail station in the City of Bridgeport. The study was funded through a federal HUD (Housing and Urban Development)-EPA-DOT (Department of Transportation) Sustainable Communities Regional Planning grant and was completed in 2013. The proposed site of Barnum Station lies between the East Side and East End neighbourhoods. Both neighbourhoods are dominated by abandoned industrial properties and vacant land, much of it contaminated. The Feasibility Study found that construction and operation of a second commuter rail station in the City of Bridgeport is physically and operationally possible, and could serve as a catalyst for the revitalization and redevelopment of the East Side and East End neighbourhoods. The proximity of the City's largest employer, Bridgeport Hospital (part of the Yale New Haven Health System) as well as the Hospital's plans for future expansion provides a ridership base for a new station, in addition to the residents of the East Side and East End [1]. 
Although the Study is not a regulatory document, the recommendations for future land use will guide development of the Barnum Station site and adjacent properties. The analyses and conceptual plans will support both the Regional TOD Pilot Program and brownfields assessment activities. Barnum Station is visioned as an anchor for mixed-use, transit-oriented development on several adjacent vacant parcels located within walking distance of the station and Bridgeport Hospital. A range of housing options, including mixed income and affordable, workforce housing is critical to supporting the residents of both the East Side and East End neighbourhoods. Large parcels available for redevelopment and suitable for commercial, office or light industrial activities are located along Seaview Avenue. High-quality transit access, improvements to the existing transportation corridors and a framework to reduce vehicular congestion are necessary to attract commercial, industrial and institutional investments.

\section{Intended program outcomes}

As the Brownfields and TOD programs have recently commenced, outcomes have not yet been realized. The outcomes of both programs are intended to complement and support one another. Through integrating social, economic and environmental considerations into both programs, the following benefits are anticipated.

\subsection{Land use and transportation improvements: Stratford town center}

Currently, development in the vicinity of Stratford's Town Center and rail station area is a mix of auto-oriented retail, commercial and residential land uses. As the rail station serves a large commuter population, over 800 additional parking spaces are needed to adequately meet current demand. Current patterns of vehicle circulation, the volume of traffic and the proximity of the exit and entrance ramps to an interstate highway (I-95) cause traffic congestion throughout the Town Center. An overpass for I-95 and a railroad bridge bisect the Town Center, effectively creating two distinct neighbourhoods with limited connections to one another. The pedestrian environment is diminished by the overpass and railroad bridge, high traffic volumes and the number of curb cuts that interrupt the sidewalk [19].

The existing infrastructure in and adjacent to the Town Center is capable of supporting development at a higher density with a mix of uses. However, traffic congestion must also be mitigated by a range of strategies that include improving the flow of traffic, increasing parking, creating a safe pedestrian environment and encouraging bus ridership through a stronger link with the existing rail service. Vacant brownfield properties within and adjacent to the TCD District must also be remediated before redevelopment of these sites can occur. Zoning regulations supportive of transit oriented development, design guidelines and improvements to the transportation system are necessary for the sustainable redevelopment of the Town Center. 
As part of the Regional TOD Program, sites with a high potential for redevelopment consistent with the community's vision for the Town Center will be identified. Assessment funding will be targeted to contaminated properties prioritized through the Regional TOD Program and with a high redevelopment potential. The intent of this coordinated approach is for the quick redevelopment of TOD supportive properties: the necessary zoning regulations will be in place to guide development activities, developers will be aware of the environmental status of the site and necessary remediation actions and the recommended infrastructure, transit and pedestrian improvements will be implemented as the Town Center is developed at a higher density.

\subsection{Transportation investment: east Bridgeport development corridor}

Over 800 acres of vacant industrial land are located in the East BridgeportSeaview Avenue Development Corridor, much of it contaminated. This corridor is unique to the Northeastern United States, as very few cities in close proximity to the New York City market and located on a major rail line have such a quantity of uninterrupted vacant land available for redevelopment.

The East Bridgeport-Seaview Avenue Development Corridor follows Seaview Avenue, a local, two-lane arterial road. From the south, the corridor is anchored by the Port of Bridgeport and the Bridgeport Regional Maritime Center. Lake Success EcoBusiness Park anchors the corridor from the north. Seaview Avenue has a very limited capacity to support the current volume of traffic, between 8,700 and 14,700 vehicles per day at various locations [1]. The condition of the road is viewed as a detriment to economic expansion, business growth and retention. A north-south "Transitway" within the corridor would link several large, vacant and underutilized industrial parcels.

Through the Regional TOD Program, travel and traffic patterns within the East Bridgeport-Seaview Avenue Development Corridor will be assessed, road improvements will be evaluated and public transit alternatives will be investigated. In addition to facilitating north-south travel between the Port of Bridgeport, the Bridgeport Regional Maritime Center and the Lake Success EcoBusiness Park, the program will determine strategies to link the region's four commuter rail stations (Fairfield Metro, Downtown Bridgeport, proposed Barnum Station and Stratford Center) and TOD districts via efficient public transit services.

EPA funded brownfield assessment activities in Bridgeport will be targeted to priority sites identified through findings from the East Bridgeport-Seaview Avenue Development Corridor analysis, as well as those identified in the completed Barnum Station Feasibility Study. In contrast to the Stratford Town Center component of the program, a greater range of land uses and development patterns are anticipated to occur in the East Bridgeport-Seaview Avenue Development Corridor. Consideration of the future use of the individual property will inform any environmental assessment activities. While these uses include transit oriented development in close proximity to the proposed Barnum Station (but most likely at a higher density than that envisioned for Stratford's Town Center), expanded industrial, institutional, commercial and office uses are also 
anticipated. Zoning regulations, transit improvements and a transportation infrastructure that supports this range of uses, but alleviates the current vehicular congestion are necessary for the revitalization of the corridor

\subsection{Greater Bridgeport transit, long range transit plan}

Greater Bridgeport Transit (GBT) provides fixed route and demand response bus service to the Greater Bridgeport Region. Service is available seven days a week and almost 5.2 million passengers utilize the service annually. A long range transit plan will assess the needs and opportunities for the expansion of GBT service throughout the Greater Bridgeport Region. Service plans will include alternatives that include rationalizing existing routes, new express and limited services, bus priority systems, bus rapid transit service along existing right-ofways, Intelligent Transportation System (ITS) elements and bus rapid transit on a separate or limited right-of-way. Schedule changes and illustrative service schedules to improve connections and pulsing between connecting services and routes traversing the regions will be developed through the Regional TOD Pilot Program. Service plans will focus on new and enhanced transit services between suburban areas, to and from employment areas and to under-served areas. Three service plan scenarios will be developed: year one, year three and year five needs.

Long term opportunities for local bus service will be determined by conceptual designs for TOD districts and the provision of local bus connections to the East Bridgeport-Seaview Avenue Development Corridor and rail stations. Local bus service plans will provide the level of access necessary for passengers to travel from residential neighborhoods to new transit corridors and hubs. In addition, the long range transit plan will include service expansion options beyond GBT's base service levels, long term fleet requirements and long range capital needs.

\subsection{Guiding principles of the regional TOD program}

Throughout the separate tasks of the Regional TOD Pilot Program and related projects, an emphasis is placed on connections, accessibility and linkages at several scales. In the immediate transit oriented development areas, a safe pedestrian environment from rail facilities to commuter parking, bus service, employment, housing, services and amenities must be provided. Developing connections between neighbourhoods, transit corridors and TOD Districts that are not solely reliant upon the automobile are equally necessary to ensuring patterns of sustainable development.

Past analyses of brownfields redevelopment projects at a national level have often found the need for coordination between agencies and departments at every level of government (local, regional, state and federal). The Brownfields and Regional TOD Programs, while both primarily federally funded, are funded through two separate agencies: the US Department of Transportation (FHWA/FTA) and the US Environmental Protection Agency [8, 9]. Some funding has also been provided by the State of Connecticut, adding an additional 
level of complexity to the project's funding structure. Both programs also require coordination with several local communities, a regional transit service provider and a regional planning organization, as well as the State of Connecticut and the federal government.

Although coordinating tasks from the two programs makes the maximum use of limited funds, the primary goal of this coordination is for the successful implementation of the redevelopment of the East Bridgeport-Seaview Avenue Development Corridor and the Stratford Transit Centered Development District. Linking transportation improvements with the assessment and ultimate clean-up of contaminated properties in both communities will provide a comprehensive blueprint for future redevelopment decisions.

\section{References}

[1] City of Bridgeport. Barnum Station Feasibility Study. 2013.

[2] United States Census. American Community Survey: Demographic and Housing Estimates. 2007-2011. Online. http://factfinder2.census.gov.

[3] United States Census. American Community Survey: Commuting Characteristics by Sex. 2007-2011. Online. http://factfinder2.census.gov.

[4] Connecticut Economic Resource Center, Inc. Bridgeport, CT: CERC Town Profile. 2012. Online. http://www.cerc.com/TownProfiles/ Customer-Images/bridgeport.pdf.

[5] City of Bridgeport. BGreen 2020. 2008.

[6] Town of Stratford. Stratford on the Housatonic, Plan of Conservation and Development (Draft). 2013.

[7] Commerce and Economic and Community Development, Ct. General Stat. 32-9 kk(a) (1) (2013).

[8] Mallach, Alan. Facing the Urban Challenge: The Federal Government and America's Older Distressed Cities. Brookings Institute. 2010.

[9] Eisen, Joel B. "Brownfields at 20: A Critical Reevaluation" Fordham Urban Law Journal, 34(2). 2006.

[10] Fogarty, Nadine and Mason Austin. Rails to Real Estate Final Report. Center for Transit Oriented Development. Oakland, CA, 2011.

[11] Connecticut Conference of Municipalities (CCM), Municipal Revenue Diversification and the Real Estate Conveyance Tax. New Haven, 2011.

[12] State of Connecticut Office of Policy and Management (OPM), Municipal Fiscal Indicators, 2007-2011. 2012. Online. http://www.ct.gov/opm/lib/ opm/igp/munfinsr/FI_2007-2011_1-15-13.pdf.

[13] Mihaescu, Oana and Rainer vom Hofe, The Impact of Brownfields on Residential Property Values in Cincinnati, Ohio: A Spatial Hedonic Approach. The Journal of Regional Analysis and Policy, 42(3), pp. 223236, 2012.

[14] National Vacant Properties Campaign. Vacant Properties: The True Costs to Communities. 2005. Online. http://www.smartgrowthamerica.org /documents/true-costs.pdf. 
[15] American Planning Association. Reuse: Creating Community-Based Brownfield Redevelopment Strategies. 2010. Online.

[16] http://www.planning.org/research/brownfields/.

[17] Chilton, Ken, Peter Schwarz and Kenneth Godwin. Final Report: Verifying the Social, Environmental and Economic Promise of Brownfields Programs. 2007.

[18] International City/County Management Association. Getting to Smart Growth II: 100 More Policies for Implementation. Online http://www.smartgrowth.org/pdf/gettosg2.pdf.

[19] United States Environmental Protection Agency. Air and Water Quality Impacts of Brownfields Redevelopment. 2011. Online.

[20] http://www.epa.gov/brownfields/sustain_plts/factsheets/air-water-fs032811-508.pdf.

[21] Town of Stratford. Choices for Stratford: Transit Centered Development Feasibility Study. 2010. 